\title{
Effect of Abnormal Posture on Quality of Life in Patients with Parkinson's Disease
}

\author{
Kyohei Mikami ${ }^{1}$, Makoto Shiraishi' ${ }^{2}$, Tsutomu Kamo ${ }^{1}$ \\ ${ }^{1}$ Noborito Neurology Clinic, Kawasaki, Japan \\ ${ }^{2}$ Division of Neurology, St. Marianna University School of Medicine, Kawasaki, Japan \\ Email: "kyo.mikami@gmail.com, shira@marianna-u.ac.jp, tkamo@c00.itscom.net
}

Received 5 February 2016; accepted 25 April 2016; published 28 April 2016

Copyright (C) 2016 by authors and Scientific Research Publishing Inc.

This work is licensed under the Creative Commons Attribution International License (CC BY). http://creativecommons.org/licenses/by/4.0/

(c) (i) Open Access

\section{Abstract}

Background: Relationship between abnormal posture and QOL of Parkinson's disease is not clear. Objectives: To clarify the association between quality of life (QOL) and abnormal posture in patients with Parkinson's disease (PD) and examine which QOL dimensions are involved. Methods: This study retrospectively examined PD patients $(n=57)$ who had undergone outpatient rehabilitation between January and March 2014. Evaluation items were Modified Hoehn Yahr (H-Y) stage, Unified Parkinson's Disease Rating Scale (UPDRS)-Part III score, Timed Up and Go test (TUG, 3-m walking) result, Parkinson's Disease Questionnaire (PDQ)-39 score, and the angle of forward and lateral trunk flexion in the standing position. Statistical analysis was performed to reveal the relationship between the total PDQ-39 score and individual evaluation items and which QOL dimensions were affected by abnormal posture due to forward or lateral flexion. Results: A total of 38 PD patients (17 men, 21 women; mean age, $73.2 \pm 8.6$ years) were enrolled. Among the evaluation items, lateral flexion angle showed a significant correlation with the total PDQ-39 score $(r=0.422$, $P=0.008$ ). PDQ-39 dimensions showing an association with forward flexion were activities of daily living $(A D L)(P=0.002)$ and communication $(P=0.007)$, whereas ADL $(P=0.004)$, communication $(P=0.021)$, and social support $(P=0.029)$ were associated with lateral flexion. Mobility was not associated with forward or lateral flexion. Conclusion: The present findings revealed a correlation between lateral flexion and QOL in PD patients. Among the PDQ-39 dimensions, ADL and communication were associated with abnormal posture.

\section{Keywords}

Parkinson's Disease, Abnormal Postural, Quality of Life, Parkinson's Disease Questionnaire (PDQ)-39

\footnotetext{
${ }^{*}$ Corresponding author.
} 


\section{Introduction}

Parkinson's disease (PD) is a progressive chronic disease with motor symptoms as the primary manifestations. The adjusted prevalence in one Japanese city was 166.8 in 2004 when calculated using the Japanese, and the adjusted crude incidence was 10.3 in 2004 when calculated using the population in this city in 1980 [1]. We experienced the variability in clinical expression of PD and characterized pathologically by the loss of pigmented neurons in the substantial nigra zone compacta, the presence of Lewy bodies, and other pathologic changes [2]. The main treatment goal for PD is to maintain quality of life (QOL) as long as possible. Schrag et al. reported depression, cognitive impairment, gait disorder, a history of falls, and impaired postural reflexes as factors influencing QOL in PD patients [3]. According to the Global Parkinson's Disease Survey Steering Committee, bipolar disease, inability to perform activities of daily living (ADL), and gait disorder were factors adversely affecting QOL [4]. As these reports show, many disease-related factors influence QOL in PD patients, and therefore, it is important to recognize and integrate clinical symptoms and patient complaints [5]. In contrast, Hagell et al. [6] provided general support for the acceptability and reliability of the PDQ-39. However, there has been no report about whether and how abnormal posture impacts QOL in PD patients.

As reported by James Parkinson in An essay on shaking palsy [7], abnormal posture has been known as a clinical manifestation of PD for a long time. Even today, abnormal posture remains the most difficult symptom to treat because it involves multiple background pathologies such as dystonia, rigidity, and proprioceptive dysfunction [8]. It is also unclear how abnormal posture affects QOL and everyday life of PD patients. Therefore, to select appropriate treatment strategies and goals, we conduct a retrospective study to clarify whether abnormal posture affects QOL in PD patients, how it affects them, and which QOL dimensions are affected. In the present study, two body angles, fore-bent and lateral-bent angles were surveyed in PD patients.

\section{Materials and Methods}

Subjects were selected from a group of 57 PD patients who had undergone outpatient rehabilitation between January and March 2014 based on the following inclusion criteria: 1) patients were judged by their neurologist to be suitable for rehabilitation; and 2) consented before undergoing evaluation of the severity of PD and the outcome of rehabilitation. Evaluation data in patient medical records were retrospectively analyzed. The indications for rehabilitation were: 1) loss of motor function that was not caused by disuse syndrome; 2) drug therapy did not fully improve motor symptoms and complications; or 3) motor symptoms and complications had worsened.

Exclusion criteria were: 1) a score of $\leq 24$ on the Mini Mental State Examination (MMSE) which tests cognition; 2) limited range of motion in the thoracic region; or 3) psychological symptoms such as severe confusion, hallucination, delusion, abnormal behavior, depression etc. or autonomic disorder. The evaluation items were used Modified Hoehn Yahr (H-Y) stage, Unified Parkinson's Disease Rating Scale (UPDRS)-Part III score. Timed Up and Go test (TUG, $3 \mathrm{~m}$ walking) result, and the angle of forward and lateral trunk flexion in the standing position were used to investigate their motor ability. By setting the posterior side of the sacrum as the standard plane, the angle between the plane and a line connecting the 7th cervical (C7) and 4th lumbar (L4) spinous processes was measured to obtain the angle of forward flexion. As for the angle of lateral flexion, the angle between the line connecting $\mathrm{C} 7$ and L4 spinous processes and a vertical line descending to the floor from the center of the line connecting the two iliac crests was measured (Figure 1). QOL in PD patients was evaluated using the Parkinson's Disease Questionnaire (PDQ)-39 scale developed by the Health Services Research Unit, University of Oxford Institute of Health Sciences, England. PDQ-39 consists of 39 questionnaire items about eight dimensions of QOL: mobility (10 items), ADL (6 items), emotional well-being (6 items), stigma (4 items), communication ( 3 items), bodily discomfort (3 items), social support (3 items), and cognition (4 items) (Table 1) [9] [10]. The use of the PDQ-39 questionnaire items in Japanese has been validated by Kawamoto et al. [11].

Statistical analysis was performed using SPSS software (Version 22 for Windows; IBM Inc., Tokyo, Japan). The relationship between the total PDQ-39 score and each evaluation item was analyzed using the Pearson correlation coefficient, and multiple linear regression analyses were performed, with angles of forward and lateral flexions as dependent variables. Biologically plausible predictors (age, sex) were included in the original model, and eight sub-scale items of PDQ-39 dimensions were used as independent variables. In all analyses, statistical significance was set at $5 \%(\mathrm{P}<0.05)$. 


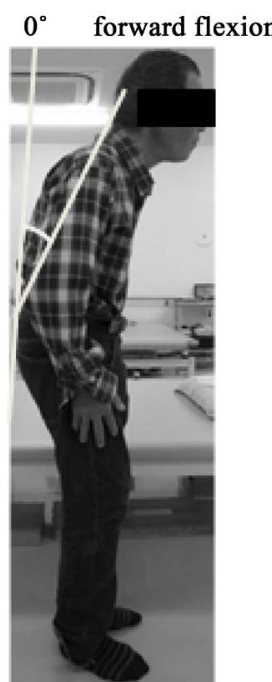

(a)

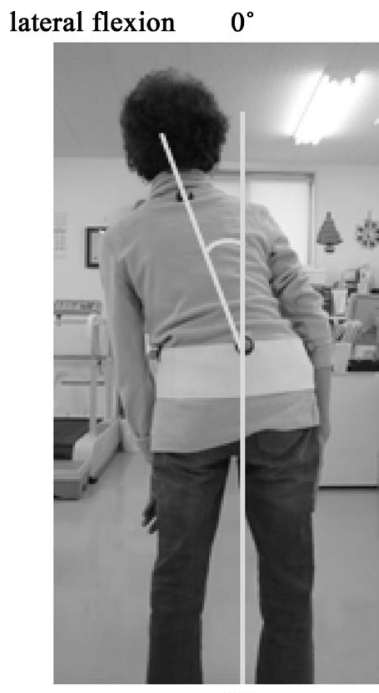

(b)

Figure 1. Upright posture measurement. (a) Angle of forward flexion; (b) Angle of lateral flexion.

Table 1. Parkinson's disease questionnaire (PDQ)-39.

\begin{tabular}{|c|}
\hline Mobility \\
\hline $\begin{array}{l}1 \text { Leisure activities } \\
2 \text { Looking after home } \\
3 \text { Carry shopping bags } \\
4 \text { Walking half a mile } \\
5 \text { Walking } 100 \text { yards } \\
6 \text { Getting around the house } \\
7 \text { Getting around in public } \\
8 \text { Need company when going out } \\
9 \text { Worry falling in public } \\
10 \text { Confined to the house }\end{array}$ \\
\hline Activities of daily living (ADL) \\
\hline $\begin{array}{l}11 \text { Washing } \\
12 \text { Dressing } \\
13 \text { Do buttons or shoe laces } \\
14 \text { Writing clearly } \\
15 \text { Cutting food } \\
16 \text { Hold a drink without spilling }\end{array}$ \\
\hline Emotional well-being \\
\hline $\begin{array}{l}17 \text { Depressed } \\
18 \text { Isolated \& lonely } \\
19 \text { Weepy or tearful } \\
20 \text { Angry or bitter } \\
21 \text { Anxious } \\
22 \text { Worried about the future }\end{array}$ \\
\hline Stigma \\
\hline $\begin{array}{l}23 \text { Felt need to conceal PD } \\
24 \text { Avoid eating/drinking in public } \\
25 \text { Embarrassed due to PD } \\
26 \text { Worried people's reactions }\end{array}$ \\
\hline Social support \\
\hline $\begin{array}{l}27 \text { Close relationships } \\
28 \text { Support from partner } \\
29 \text { Support from family or friends }\end{array}$ \\
\hline
\end{tabular}




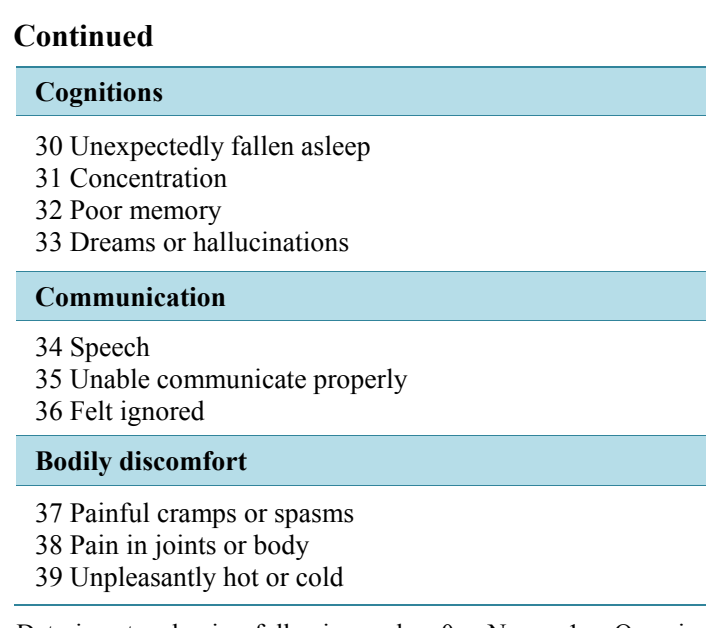

Data is entered using following codes: $0=$ Never, $1=$ Occasionally, 2 = Sometimes, 3 = Often, 4 = Always (or cannot do at all, if applicable.

Table 2. Baseline characteristics of subjects with Parkinson's disease.

\begin{tabular}{|c|c|}
\hline Characteristics & Study participants $(\mathrm{n}=38)$ \\
\hline Age $(y r)$ & $73.2 \pm 8.6$ \\
\hline $\operatorname{Sex}(n)$ & 17 men, 21 women \\
\hline Disease duration (yr) & $8.8 \pm 5.9$ \\
\hline MMSE (score) & $27.3 \pm 1.9$ \\
\hline H-Y stage & $2.8 \pm 0.7$ \\
\hline Forward flexion $\left({ }^{\circ}\right)$ & $10.7 \pm 17.5$ \\
\hline Lateral flexion $\left({ }^{\circ}\right)$ & $10.1 \pm 12.9(\mathrm{R}: 23)$ \\
\hline UPDRS Part III (score) & $16.9 \pm 10.2$ \\
\hline Postural stability (score) (UPDRS item 30) & $1.7 \pm 1.1$ \\
\hline TUG (sec) & $13.3 \pm 5.8$ \\
\hline \multirow[t]{2}{*}{ L-Dopa (mg) } & $100 \%(\mathrm{n}=38)$ \\
\hline & $373.7 \pm 120.7$ \\
\hline \multirow[t]{4}{*}{ Dopamine agonist (mg) } & $89.5 \%(n=34)$ \\
\hline & Pramipexole $1.86 \pm 0.84(\mathrm{n}=21)$ \\
\hline & Ropinirole $7.25 \pm 2.64(\mathrm{n}=11)$ \\
\hline & Rotigotine $12 \pm 3.18(\mathrm{n}=2)$ \\
\hline MAO-B blocker (mg) & $57.9 \%(\mathrm{n}=22)$ \\
\hline Amantadine (mg) & $26.3 \%(\mathrm{n}=10)$ \\
\hline COMT inhibitor (mg) & $26.3 \%(n=10)$ \\
\hline
\end{tabular}

MMSE: Mini Mental State Examination H-Y stage: Modified Hoehn \& Yahr Scale stage, TUG : Timed Up and Go test UPDRS: Unified Parkinson's Disease Rating Scale.

This retrospective study was approved by the Ethics Committee of the Japan Primary Care Association (approval \#, 2015-002).

\section{Results}

Subjects were 38 patients (17 men, 21 women; mean age, $73.2 \pm 8.6$ years) with mean disease duration of $8.8 \pm$ 5.9 years, an MMSE score of $27.3 \pm 1.9$, the H-Y stage of $2.8 \pm 0.7$, and a UPDRS-Part III score of $16.9 \pm 10.2$ (Table 2). Patients' clinical characteristics are shown in Table 2. A period of time measured the evaluation of PDQ-39 was $37.4 \pm 10.9$ minutes.

A significant correlation was observed between the PDQ-39 score and lateral flexion angle $(r=0.422, P=$ 
0.008; Figure 2(a)), but not age, MMSE, forward flexion angle (Figure 2(b)), H-Y stage (Figure 2(c)), Part III of UPDRS (Figure 2(d)), or TUG.

PDQ-39 dimensions affected by forward flexion were ADL $(\mathrm{P}=0.002)$ and communication $(\mathrm{P}=0.007)$, but not mobility (Table 3 ), whereas those affected by lateral flexion angle were ADL $(\mathrm{P}=0.004)$, communication $(\mathrm{P}=0.021)$, and social support $(\mathrm{P}=0.029)$, but not mobility (Table 4$)$.

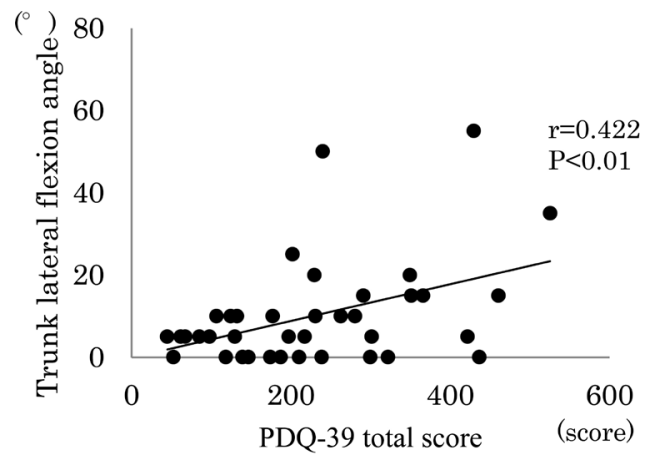

(a)

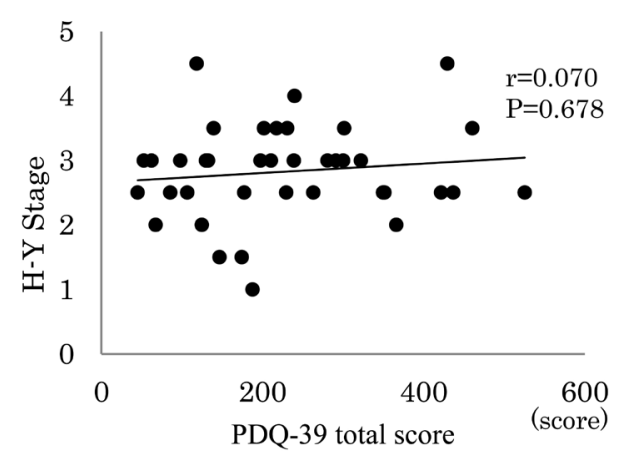

(c)

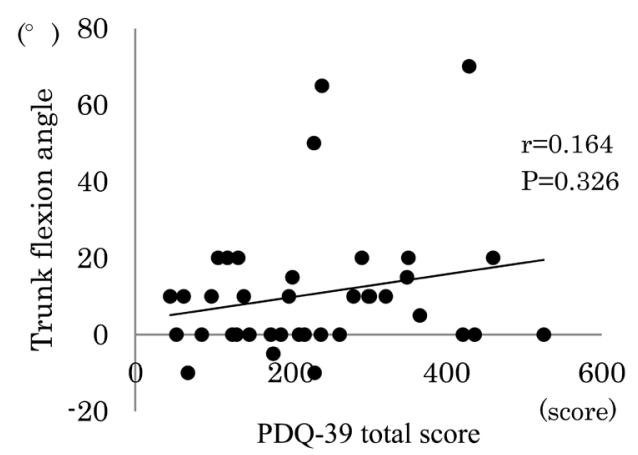

(b)

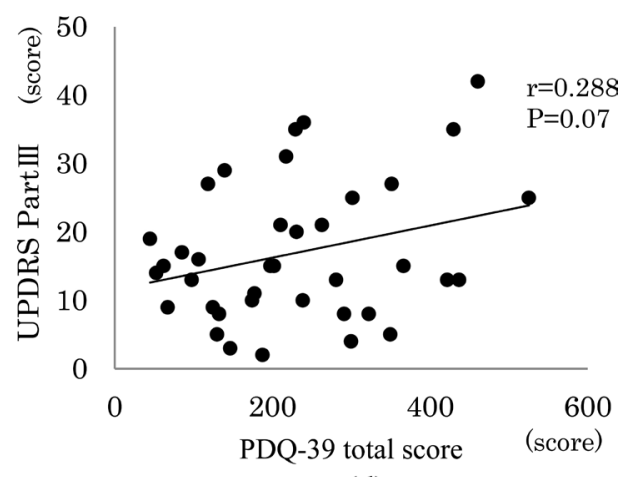

(d)

PDQ-39: Parkinson's Disease Questionnaire-39; H-Y stage: Modified Hohen \& Yahr stage; UPDRS: Unified Parkinson's Disease Rating Scale.

Figure 2. Correlation between PDQ-39 and abnormal posture, H-Y stage, or Part Ш of UPDRS. (a) Correlation of the PDQ-39 total score and the trunk lateral flexion angle; (b) Correlation of the PDQ-39 total score and the trunk flexion angle; (c) Correlation of the PDQ-39 total score and H-Y stage; (d) Correlation of the PDQ-39 total score and UPDRS Part III.

Table 3. PDQ-39 dimensions associated with forward flexion.

\begin{tabular}{cccc}
\hline & $\beta$ & t value & P value \\
\hline Sex & 0.027 & 0.183 & 0.856 \\
Age & -0.118 & -0.742 & 0.464 \\
Mobility & 0.034 & 0.153 & 0.879 \\
Activities of daily living & 0.876 & 3.348 & $0.002^{*}$ \\
Emotional well-being & -0.187 & -0.948 & 0.352 \\
Stigma & -0.384 & -1.706 & 0.1 \\
Social support & 0.261 & 1.114 & 0.275 \\
Cognition & 0.175 & 0.883 & 0.385 \\
Communication & -0.667 & -2.957 & $0.007^{*}$ \\
Bodily discomfort & -0.045 & -0.236 & 0.815 \\
\hline
\end{tabular}

$$
{ }^{*} \mathrm{P}<0.05 \text {. }
$$


Table 4. PDQ-39 dimensions associated with lateral flexion.

\begin{tabular}{cccc}
\hline & $\beta$ & $\mathrm{t}$ value & P value \\
\hline Sex & 0.214 & 0.433 & 0.669 \\
Age & -0.153 & -1.093 & 0.285 \\
Mobility & 0.21 & 1.07 & 0.294 \\
Activities of daily living & 0.736 & 3.185 & $0.004^{*}$ \\
Emotional well-being & -0.243 & -1.397 & 0.174 \\
Stigma & -0.391 & -1.968 & 0.06 \\
Social support & 0.479 & 2.318 & $0.029^{*}$ \\
Cognition & 0.164 & 0.935 & 0.359 \\
Communication & -0.491 & -2.465 & $0.021^{*}$ \\
Bodily discomfort & 0.024 & 0.143 & 0.888 \\
\hline
\end{tabular}

${ }^{*} \mathrm{P}<0.05$.

\section{Discussion}

The findings of this study showed a significant correlation between the total PDQ-39 score and the angle of lateral flexion, suggesting that abnormal posture due to lateral flexion affects QOL in these patients (Figure 2(a)). Again, despite conventional belief, the severity of disease or mobility which includes balancing ability was not associated with the PDQ-39 score (Figure 2(c), Figure 2(d)), suggesting that these factors do not influence QOL. Previous studies of PD patients showed the involvement of motor symptoms in QOL [12] and the improvement of QOL through rehabilitation of motor symptoms [13]-[17]. On the other hand, motor function determined using the Part III of UPDRS did not correlate strongly with QOL in a study conducted by Karlsen et al. of 233 PD patients and 100 healthy elderly individuals [5]. Grosset et al. also reported that QOL was affected by the severity of the disease or treatment approach in only $17.3 \%$ of PD patients [18]. These findings together suggest that the QOL of PD patients is affected by abnormal posture, especially lateral flexion, but not necessarily by the severity of disease or mobility.

This study also investigated the association between PDQ-39 dimensions and abnormal posture due to forward or lateral flexion. A previous study of health-related QOL in patients with chronic diseases reported the importance of evaluating not only the total PDQ-39 score, but also individual QOL dimensions [19]. In our study, the angles of forward and lateral flexion affected ADL, but not mobility (Table 3, Table 4). The mobility section of PDQ-39 consists of questionnaire items primarily about ambulation and outdoor activities. On the other hand, the questionnaire items in the ADL section are about movement applied in daily activities such as dining and dressing [11]. The findings of this study indicate that PD patients with abnormal posture have problems with the application of movement in ADL, but not the movement itself. Therefore, it may be important for PD patients with abnormal posture to undergo the rehabilitation of movements related to ADL, in addition to the improvement of their posture and walking.

Among the QOL dimensions, the loss of social support was also a dimension involved in lateral flexion (Table 4). The social support section of PDQ-39 consists of questionnaire items on the support from family and close friends. The findings of this study indicate that PD patients with more severe lateral flexion feel strongly that they need support from others or are not provided with enough support. Cheng et al. [20] urged establishment of a team for the management of PD patients because of the various evaluation criteria and procedures. ver den Marck et al. also reported that QOL was significantly better when treatment was performed by a multidisciplinary team than by a physician alone [21]. These findings suggest that support from people around the patient, such as family members and healthcare professionals, was more important for PD patients with abnormal posture to maintain and enhance long-term QOL than for those without abnormal posture. Hagell et al. [6] pointed that the sub-scale items appeared overly complex and the meaning of scale is unclear. In this study, we should interpret as useful tool regarding scale items including PDD-39 sub-scale used to evaluate QOL, although these results may have been slight suboptimal.

In this study, subjects were selected in accordance with specific selection criteria, but because this was a sin- 
gle institution study with a relatively small number of patients, selection bias might have resulted. In addition, because this study involved a single observation period, a long-term study, and reliability of the evaluation approach are needed to investigate the relationship between postural changes and QOL.

\section{Conclusion}

A correlation between lateral flexion and QOL in patients with PD was observed in this study. Among the PDQ-39 dimensions, ADL and communication were revealed as factors associated with abnormal posture in PD.

\section{Acknowledgements}

No funding received to conduct this study.

\section{Conflict of Interest}

The authors have no conflict of interest to report.

\section{References}

[1] Yamawaki, M., Kusumi, M., Kowa, H. and Nakashima, K. (2009) Changes in Prevalence and Incidence of Parkinson's Disease in Japan during a Quarter of a Century. Neuroepidemiology, 32, 263-269. http://dx.doi.org/10.1159/000201565

[2] Gibb, W.R.G. and Lees, A.J. (1988) The Relevance of the Lewy Body to the Pathogenesis of Idiopathic Parkinson's Disease. Journal of Neurology, Neurosurgery, and Psychiatry, 51, 745-752. http://dx.doi.org/10.1136/jnnp.51.6.745

[3] Schrag, A., Jahanshahi, M. and Quinn, N. (2000) What Contributes to Quality of Life in Patients with Parkinson's Disease? Journal of Neurology, Neurosurgery, and Psychiatry, 69, 308-312. http://dx.doi.org/10.1136/jnnp.69.3.308

[4] Global Parkinson's Disease Survey Steering Committee (2002) Factors Impacting on Quality of Life in Parkinson's Disease: Results from an International Survey. Movement Disorders, 17, 60-67. http://dx.doi.org/10.1002/mds.10010

[5] Karlsen, K.H., Larsen, J.P., Tandberg, E. and Maeland, J.G. (1999) Influence of Clinical and Demographic Variables on Quality of Life in Patients with Parkinson's Disease. Journal of Neurology, Neurosurgery, and Psychiatry, 66, 431435. http://dx.doi.org/10.1136/jnnp.66.4.431

[6] Hagell, P. and Nygren, C. (2007) The 39-Item Parkinson's Disease Questionnaire (PDQ-39) Revisited. Journal of Neurology, Neurosurgery, and Psychiatry, 78, 1191-1198. http://dx.doi.org/10.1136/jnnp.2006.111161

[7] Parkinson, J. (2002) An Essay on the Shaking Palsy 1817. The Journal of Neuropsychiatry \& Clinical Neurosciences, 14, 223-236. http://dx.doi.org/10.1176/jnp.14.2.223

[8] Doherty, K.M., van de Warrenburg, B.P., Peralta, M.C., Silveira-Moriyama, L., Azulay, J.P., Gershanik, O.S. and Bloem, B.R. (2011) Postural Deformities in Parkinson's Disease. The Lancet Neurology, 10, 538-549. http://dx.doi.org/10.1016/S1474-4422(11)70067-9

[9] Peto, V., Jenkinson, C., Fitzpartrick, R. and Greenhall, R. (1995) The Development and Validation of a Short Measure of Functioning and Well Being for Individuals with Parkinson's Disease. Quality of Life Research, 4, 241-248. http://dx.doi.org/10.1007/BF02260863

[10] Jenkinson, C., Fitzpatrick, R., Peto, V., Greenhall, R. and Hyman, N. (1997) The Parkinson's Disease Questionnaire (PDQ-39): Development and Validation of Parkinson's Disease Summary Index Score. Age Ageing, 26, 353-357. http://dx.doi.org/10.1093/ageing/26.5.353

[11] Kohmoto, J., Ohbu, S., Nagaoka, M., Suzukamo, Y., Kihira, T., Mizuno, Y., Ito, Y., Yamaguti, T., Ohashi, Y., Fukuhara, S. and Kondo, T. (2003) Validation of the Japanese Version of the Parkinson's Disease Questionnaire. Journal of Clinical Neurology, 43, 71-76.

[12] Moore, O., Peretz, C. and Giladi, N. (2007) Freezing of Gait Affects Quality of Life of Peoples with Parkinson's Disease beyond Its Relationship with Mobility and Gait. Movement Disorders, 22, 2192-2195. http://dx.doi.org/10.1002/mds.21659

[13] Ellis, T., de Goede, C.J., Feldman, R.G., Wolters, E.C., Kwakkel, G. and Wagenaar, R.C. (2005) Efficacy of a Physical Therapy Program in Patients with Parkinson's Disease: A Randomised Controlled Trial. Archives of Physical Medicine and Rehabilitation, 86, 626-632. http://dx.doi.org/10.1016/j.apmr.2004.08.008

[14] Schmitz-Hübsch, T., Pyfer, D., Kielwein, K., Fimmers, R., Klockgether, T. and Wüllner, U. (2005) Qigong Exercise for the Symptoms of Parkinson's Disease: A Randomized, Controlled Pilot Study. Movement Disorders, 21, 543-548. http://dx.doi.org/10.1002/mds.20705

[15] Burini, D., Farabollini, B., Iacucci, S., Rimatori, C., Riccardi, G., Cappecci, M., Provinciali, L. and Ceravolo, M.G. 
(2006) A Randomised Controlled Cross-Over Trial of Aerobic Training versus Qigong in Advanced Parkinson's Disease. Europa Medicophysica, 42, 231-238.

[16] Ashburn, A., Fazakarley, L., Ballinger, C., Pickering, R., McLellan, L.D. and Fitton, C. (2007) A Randomised Controlled Trial of a Home-Based Exercise Programme to Reduce Risk of Falling among People with Parkinson's Disease. Journal of Neurology, Neurosurgery, and Psychiatry, 78, 678-684. http://dx.doi.org/10.1136/jnnp.2006.099333

[17] Goodwin, V.A., Richards, S.H., Taylor, R.S. and Campbell, J.L. (2008) The Effectiveness of Exercise Interventions for Patients with Parkinson's Disease: A Systematic Review and Meta-Analysis. Movement Disorders, 23, $226-233$. http://dx.doi.org/10.1002/mds.21922

[18] Grosset, D., Taurah, L., Burn, D.J., MacMahon, D., Forbes, A., Turner, K., Bowron, A., Walker, R., Findley, L., Foster, O., Patel, K., Clough, C., Castleton, B., Smith S., Carey, G., Murphy, T., Hill, J., Brechany, U., McGee, P., Reading, S., Brand, G., Kelly, L., Breen, K., Ford, S., Baker, M., Williams, A., Hearne, J., Qizilbash, N. and Chaudhuri, K.R. (2007) A Multicenter Longitudinal Observational Study of Changes in Self Reported Health Status in People with Parkinson's Disease Left Untreated at Diagnosis. Journal of Neurology, Neurosurgery, and Psychiatry, 78, 465-469. http://dx.doi.org/10.1136/jnnp.2006.098327

[19] Ellerhorst-Ryan, J.M. (1996) Instruments to Measure Spiritual Status. In: Spilker, B., Ed., Quality of Life and Pharmacoeconomics in Clinical Trial, Lippincott Williams \& Wilkins, New York, 145-153.

[20] Cheng, E.M., Tonn, S., Swain-Eng, R., Factor, S.A., Weiner, W.J. and Bever Jr., C.T. (2010) Quality Improvement in Neurology: AAN Parkinson Disease Quality Measures: Report of the Quality Measurement and Reporting Subcommittee of the American Academy of Neurology. Neurology, 75, 2021-2027. http://dx.doi.org/10.1212/WNL.0b013e3181ff96dd

[21] Ven der Marck, M.A., Bloem, B.R., Borm, G.F., Overeem, S., Munneke, M. and Guttman, M. (2013) Effectiveness of Multidisciplinary Care for Parkinson's Disease: A Randomized, Controlled Trial. Movement Disorders, 28, 605-611. http://dx.doi.org/10.1002/mds.25194 